to another, but was between 20 and $45 \mathrm{~mm}$. $\mathrm{Hg}$ in the children studied.

This work was supported by a grant from the Joint Research Board of the Hospital for Sick Children. I am grateful to $\mathrm{Mr}$. D. J. Waterston, Mr. E. Aberdeen, Dr. G. R. Graham, Dr. M. Hawksley, Dr. W. J. Glover, and Dr. R. W. Cope, whose interest and co-operation in the operating-theatre have made this work possible. I am especially grateful to Dr. G. Pampiglione for his invaluable help and encouragement.

\section{REFERENCES}

Arfel, G., Weiss, J., and Du Bouchet, N. (1961). Cerebral Anoxia and the Electroencephalogram, edited by $\mathrm{H}$. Gastaut and J. S. Meyer, Chapt 24. Thomas, Springfield, Ill.
Brechner, V. L., Kavan, E. M., and Dillon, J. B. (1959). F. thorac. Surg., Duffy, P. E., and Caliva, F. S. (1961). Neurology (Minneap.), 11, 742.

Kavan, E. M., and Brechner, V. L. (1961). Anesth. Analg. Curr. Res., $40,418$.

Kety, S. S. (1950). Amer. f. Med., 8, 205.

Moyer, J. H., Miller, S. I., and Snyder, H. (1954). F. appl. Physiol., 7, 245.

Pampiglione, G. (1956). Proc. Electrophysiol. Technol. Ass., 7, 80.

- and Waterston, D. J. (1958). Electroenceph. Clin. Neurophysiol., 10, 354 .

- (1961). Cerebral Anoxia and the Electroencephalogram, edited by H. Gastaut and J. S. Meyer, Chapt. 25. Thomas, Springfield, IIl.

Storm van Leeuwen, W., Mechelse, K., Kok, L., and Zierfuss, E. (1961). Ibid., Chapt. 27.

Thies-Puppel, H., and Wiemers, K. (1961). Ibid., Chapt. 28.

\title{
Cushing's Syndrome Associated with Carcinoma of the Bronchus in a Patient with Normal Plasma Electrolytes
}

\author{
M. FRIEDMAN,* M.B., B.CH., M.R.C.P.ED. ; J. R. MIKHAIL, † M.R.C.S., L.R.C.P. ; \\ K. D. BHOOLA, $\ddagger$ M.B., B.CH., B.A.O., PH.D.
}

Brit. med. F., 1965, 1, 27-29

The original description of the association between bronchogenic carcinoma and Cushing's syndrome was given by Brown (1928). Since Thorne (1952) reported two cases, 24 additional reports of similar cases have appeared in the literature, which is reviewed by Allott and Skelton (1960). In most cases the clinical features of Cushing's syndrome have been absent. Hypokalaemic alkalosis was found in all cases with the notable exceptions of the single cases reported by Rosenthal (1957), MacPhee (1959), and Billinghurst et al. (1961). Weakness or paralysis due to low potassium has often been the presenting and predominant symptom of the disease.

This report concerns a patient who presented with an oatcell carcinoma of the bronchus and who was found to have biochemical evidence of Cushing's syndrome, the diagnosis subsequently being confirmed at necropsy. However, throughout the period of observation no abnormality in her plasma electrolytes was observed.

Many investigators have used the plasma potassium and bicarbonate as a screening procedure for Cushing's syndrome in patients with carcinoma of the bronchus. Reliance on this alone is bound to lead to cases being missed, and hence the recognition that the disease can occur in the presence of normal plasma electrolytes is of some practical importance.

\section{Case Report}

A 59-year-old woman was seen at the Willesden Chest Clinic in June 1963, having been referred after a routine mass chest $x$-ray examination at her place of work. She gave a history of a cough, wheezing, and dyspnoea on exertion of three to four months' duration. One month before being seen she had a small haemoptysis followed by slight blood-staining of her sputum for a few days. She had smoked 10-20 cigarettes a day for the past 20 years. On examination she had signs of collapse in the right lower zone of the chest. There was no clubbing. No glands, liver, or spleen were palpable. B.P. was $160 / 90$. $X$-ray examination showed an opacity in the hilar region of the right lung. Sputum cytology

* Medical Unit, University College Hospital, London.

+ Willesden Chest Clinic, London.

¥ Central Middlesex Hospital, London. revealed no carcinoma cells. Bronchoscopy demonstrated a tumour of the right-lower-lobe bronchus, which was proved histologically to be an invasive oat-cell carcinoma. Early in July 1963 an exploratory thoracotomy (Mr. J. Jackson) revealed a globular neoplastic mass invading the apical and posterior segments of the right middle and upper lobe. The carinal and peribronchial glands were greatly enlarged. Infiltration of the oesophagus was present. The neoplasm was thought to be inoperable. The patient was discharged home after an uneventful post-operative recovery. She was not given radiotherapy because of the known danger of temporary enlargement of mediastinal glands due to oedema, giving rise to tracheal compression.

At the beginning of September she was readmitted to hospital. She complained of chest pain, dyspnoea, wheezing, a productive cough, and anorexia. On examination at this time she was in poor condition. There were signs of collapse at the right base. Both the supraclavicular and cervical glands were enlarged. The liver was palpable $5 \mathrm{~cm}$. below the costal margin. B.P. was 98/60. There was no pigmentation, no signs of Cushing's syndrome, and no muscular weakness.

Investigations.-Haemoglobin 13.5 g./100 ml.; E.S.R. $55 \mathrm{~mm}$. in one hour; W.B.C. $10,400 /$ c.mm. Total protein 6.5 g. $/ 100 \mathrm{ml}$. Thymol turbidity 1.2 units. Alkaline phosphatase $16 \mathrm{~K}$.A. units; sodium $133 \mathrm{mEq} / \mathrm{l}$. ; potassium $4.5 \mathrm{mEq} / 1$. ; chloride $92 \mathrm{mEq} / \mathrm{l}$. ; bicarbonate $27.4 \mathrm{mEq} / 1$. ; blood urea $26 \mathrm{mg} . / 100 \mathrm{ml}$.; serum calcium $8.9 \mathrm{mg} . / 100 \mathrm{ml}$. ; plasma phosphorus $2.7 \mathrm{mg} . / 100 \mathrm{ml}$.; fasting blood glucose $96 \mathrm{mg} . / 100 \mathrm{ml}$. ; blood glucose two hours after a meal $98 \mathrm{mg} . / 100 \mathrm{ml}$. Absolute eosinophil count 8/c.mm.

Adrenal Function.-Because of the patient's low blood-pressure and lethargic state the plasma cortisol was measured, as a hypoadrenal state due to destruction of the adrenal glands by secondary carcinomatous deposits was suspected. This was performed by one of us (M. F.) by the method described by Mattingly (1962). Much to our surprise this revealed a level of $37.1 \mu \mathrm{g} . / 100 \mathrm{ml}$. (normal at 9 a.m. 8-26 $\mu \mathrm{g} . / 100 \mathrm{ml}$.). Furthermore, there was a loss of the normal diurnal rhythm of plasma cortisol with a midnight level of $21 \mu \mathrm{g} . / 100 \mathrm{ml}$. (normal less than $6 \mu \mathrm{g} . / 100 \mathrm{ml}$.) The 24-hour total urinary 17-hydroxycorticosteroids (17-OHCS) were $34 \mathrm{mg} . / 24$ hours. An A.C.T.H. stimulation test was performed, using known biologically active gel at a dosage of 40 units 12-hourly intramuscularly. This produced a rise in the total $17-\mathrm{OHCS}$ to $165 \mathrm{mg}$. on the second day and to $215 \mathrm{mg}$. on the third day of the test. There was also an abnormally large rise in the plasma cortisol to $83 \mu \mathrm{g} . / 100 \mathrm{ml}$. on the first day, $178 \mu \mathrm{g} . /$ 
$100 \mathrm{ml}$. on the second day, and $162 \mu \mathrm{g} . / 100 \mathrm{ml}$. on the third day (see Chart). The plasma cortisol was measured at 2 p.m. on each day of A.C.T.H. administration, the specimen being taken five hours after the 9 a.m. dose of A.C.T.H., which corresponds approximately to the time of maximal adrenal stimulation by exogenous A.C.T.H. A dexamethasone suppression test was performed. She was given $2 \mathrm{mg}$. of dexamethasone a day for two days, followed by 4,6 , and $8 \mathrm{mg}$. a day, each for two days. This showed practically no suppression of the excretion of urinary 17-OHCS, which was $17 \mathrm{mg} . / 24$ hours on the second day of $8 \mathrm{mg}$. of dexamethasone. Likewise the plasma cortisol showed practically no evidence of suppression even by the larger dose of dexamethasone. Throughout the investigation the patient's plasma potassium remained above $4.5 \mathrm{mEq} / 1$. and the plasma bicarbonate below $28 \mathrm{mEq} / 1$.

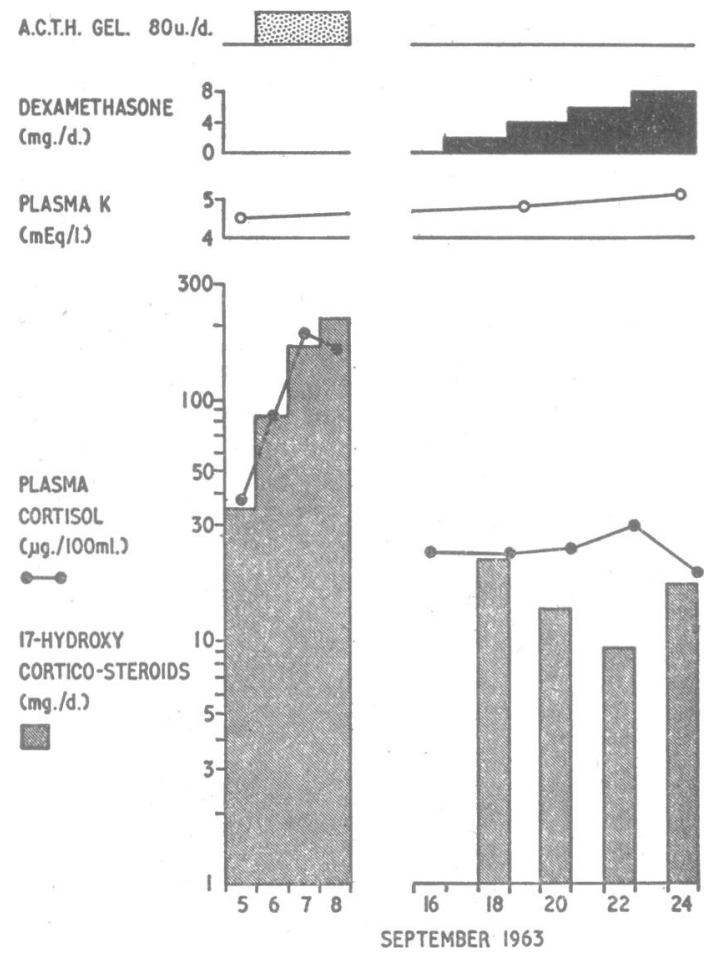

Results of plasma cortisol and urinary 17-OHCS plotted on a semi-log scale. The resting levels and those following the administration of A.C.T.H. and dexamethasone are shown. The plasma potassium is also plotted. For interpretation see text.

Progress.-Her condition gradually deteriorated. She became increasingly breathless owing to obstruction of the trachea by mediastinal glands. She died in the middle of October, four months after presentation. At the time of her death there were no clinical signs of adrenal overactivity. She had never had glycosuria at any time, nor did she become hypertensive.

Post-mortem Examination.-This was performed by Dr. U. F. Rowlatt, who found a locally invasive oat-cell carcinoma of the right main bronchus, involving local lymph nodes, pericardium, and the roof of the left atrium. Distant metastases were present in the liver. The brain was normal, with no macroscopic or microscopical evidence of metastases in the region of the pituitary gland. Both adrenals were enlarged: the left weighed $47.5 \mathrm{~g}$. and the right $12.3 \mathrm{~g}$. A small discrete metastasis was present in the right adrenal. Histological examination of the adrenal glands showed hyperplasia of the adrenal cortex.

\section{Discussion}

The diagnosis of gross adrenal overactivity in this case has been adequately established. Both the resting plasma cortisol and urinary 17-OHCS were elevated. Moreover, the normal diurnal rhythm of plasma cortisol was lost. The response of the adrenals to A.C.T.H. stimulation was grossly abnormal, as reflected by both the plasma and the urinary corticosteroid levels. The adrenal production of corticosteroids was not significantly suppressed by dexamethasone in large doses. The final confirmation of diagnosis was obtained at post-mortem examination by the demonstration of large adrenals and hyperplasia histologically.

There has been much speculation regarding the direct causal relationship between "non-endocrine" neoplasms and coexisting adrenocortical hyperfunction. For some time the production of A.C.T.H. or an A.C.T.H.-like substance produced by the tumour material has been suspected. Only recently has it been possible, by the development of more refined techniques, to demonstrate increased A.C.T.H.-like material in both the plasma and the extracts of tumour tissue obtained from patients with non-endocrine tumours associated with adrenal hyperfunction (Holub and Katz, 1961 ; Meador et al., 1962 ; Scholz et al., 1963). In our case the lack of adrenal suppression by large doses of dexamethasone indicates that this extrapituitary site of A.C.T.H. or A.C.T.H.-like substance is acting autonomously and is not influenced by circulating endogenous steroids. The fact that we were able to produce a significant increase in adrenal function by A.C.T.H. indicates that at the time of the test our patient's adrenals were not being maximally stimulated by the abnormal substance produced by the carcinoma. This could be due to the fact either that the neoplastic tissue can produce only a limited quantity of A.C.T.H.-like substance or that the case was diagnosed at a very early stage. In another case of this disease studied by one of us (M. F.), in which an A.C.T.H.-stimulation test was performed, there was no rise either in the plasma cortisol or in the 17-ketogenic steroids. In that case the resting control plasma cortisol and 17-ketogenic steroids were much higher than in the present case.

Most of the cases of adrenal overactivity associated with extra-adrenal neoplasms have been remarkable in that they demonstrated none of the usual clinical stigmata of Cushing's syndrome, although the chemical and anatomical evidence of hyperadrenocorticism has been present. Some of the patients, however, have developed hypertension, diabetes, and very occasionally the typical facies. A possible explanation advanced for this is that these patients do not live long enough to develop the effects of the increased circulating cortisol. However, this does not seem to be an entirely satisfactory explanation, as one often sees the extremely rapid onset of side-effects following the administration of corticosteroids therapeutically. It may well be that the final steroid produced by the adrenal, under the stimulus of the A.C.T.H.-like substance elaborated by the neoplasm, is in some way different from the normal corticosteroids produced under the influence of pituitary A.C.T.H.

The present case showed absolutely no clinical signs remotely suggestive of Cushing's syndrome in spite of the significantly elevated urinary and plasma-corticosteroid levels, which if this were an example of " ordinary Cushing's syndrome" would almost certainly have produced clinical manifestations of the disease. The method used for the cortisol determinations measures plasma 11-hydroxycorticosteroids (11-OHCS) as a group. In the human these consist of aldosterone, corticosterone, and cortisol. The latter probably accounts for $95 \%$ of the endogenous production of 11-OHCS. It is possible that the adrenals are producing an 11-OHCS, other than one of the above three, which is determined by our method for plasma cortisol and is excreted in the urine as the usual breakdown product.

The absence of a hypokalaemic alkalosis in our case is of interest as some authors have placed great emphasis on this aspect of the syndrome (Bagshawe, 1960). The exact mechanism of the production of the electrolyte changes are at present little understood. Electrolyte changes in Cushing's syndrome unassociated with neoplasm are uncommon (Soffer et al., 1955; Bayliss, 1957 ; Mason et al., 1958). An increased aldosterone production has been considered to explain the hypokalaemic alkalosis, but in all except three cases where this has been measured low values of aldosterone have been obtained (Lock- 
wood, 1958 ; Webster et al., 1959). The occurrence of the electrolyte changes may merely be a reflection of the severity of the disease and its duration. It is probable that our case was diagnosed very early in relation to the onset of the adrenal overactivity, and had the patient lived long enough it is likely that she might have developed the electrolyte changes. Her death was due to tracheal compression by the neoplasm and not to adrenal overactivity as is usual in these cases. The early or mild case may well escape detection, and in our case the diagnosis was made only by doing the right investigation for the wrong reason. It may well be that what we believe to be the typical case of this disease is in fact the late severe case, the milder earlier cases being missed.

\section{Summary}

A case of Cushing's syndrome associated with a carcinoma of the bronchus is described. The unusual features were the complete absence of physical signs of Cushing's syndrome and the presence of normal plasma electrolytes. It is suggested that this may have been a very early example of this disease, which may be missed because of lack of clinical or biochemical abnormalities that would direct attention to more detailed investigation of the adrenal gland. Alternatively, the hyperplastic adrenal may be producing an 11-hydroxycorticosteroid other than cortisol, determined by our method for plasma cortisol and excreted in the urine as the usual breakdown products.
We are grateful to Dr. C. H. C. Toussaint for allowing us to publish this report, and to Dr. R. A. B. Drury and Dr. U. F. Rowlatt for performing the post-mortem examination. Dr. P. M. Sutton kindly prepared and reported on the adrenal-gland sections. We are grateful to Professor C. E. Dent for helpful criticism and advice.

\section{REFERENCES}

Allott, E. N., and Skelton, M. O. (1960). Lancet, 2, 278.

Bagshawe, K. D. (1960). Ibid., 2, 284.

Bayliss, R. I. S. (1957). Proc. roy. Soc. Med., 50, 761.

Billinghurst, J. R., Thould, A. K., Galpin, O. P., and Hinton, J. M. (1961). Brit. med. F., 2, 490

Brown, W. H. (1928). Lancet, 2, 1022.

Holub, D. A., and Katz, F. H. (1961). Clin. Res. Proc., 9, 194.

Lockwood, C. H. (1958). Canad. med. Ass. 7., 79, 728.

MacPhee, I. W. (1959). Brit. F. Surg., 46, 456.

Mason, A. S., Richardson, J. E., and King, C. E. (1958). Lancet, 2, 649. Mattingly, D. (1962). 7. clin. Path., 15, 374.

Meador, C. K., Liddle, G. W., Island, D. P., Nicholson, W. E., Lucas, C. P., Nuckton, J. G., and Luetscher, J. A. (1962). भ. clin. Endocr., 22, 693.

Rosenthal, F. D. (1957). Brit. med. 7., 2, 139.

Scholz, D. A., Riggs, B. L., Bahn, R. C., and Liddle, G. W. (1963). Proc. Mayo Clin., 38, 45.

Soffer, L. J., Eisenberg, J., Iannaccone, A., and Gabrilove, J. L. (1955). In Ciba Foundation Colloquia on Endocrinology, edited by G. E. W. Wolstenholme and M. P. Cameron, vol. 8, p. 487. Churchill, London.

Thorne, M. G. (1952). Guy's Hosp. Rep., 101, 251.

Webster, G. D., jun., Touchstone, J. C., and Suzuki, M. (1959). F. clin. Endocr., 19, 967.

\title{
Reactions to Total Dose Intravenous Infusion of Iron Dextran (Imferon)
}

\author{
BARBARA CLAY,* M.R.C.S., L.R.C.P., D.OBST.R.C.o.G. ; B. ROSENBERG,* M.B., B.CH. ; \\ NANITA SAMPSON,* M.B., B.S., D.oBST.R.C.o.G.; S. I. SAMUELS,* M.B., B.CH., D.oBST.R.C.O.G.
}

Brit. med. F., 1965, 1, 29-31

Iron-deficiency anaemia is still the most common problem encountered during pregnancy, especially among women of the lower social classes. It occurs frequently in Hull, where over a five-month period selected patients were given parenteral iron by the " total dose infusion" method discussed below.

Antenatal treatment is aimed at achieving a haemoglobin level of at least $80 \%$ (Haldane) before term (Davidson, 1957; Giles and Burton, 1960). Oral iron is routinely prescribed at the antenatal clinics, and is eminently satisfactory provided the patient can tolerate it and remembers to take it.

Parenteral iron has the advantage that it is seen to be given and the dose is therefore known. Intramuscular iron, however, has the disadvantages of staining, which may occur despite the careful use of a " $Z$ "-shaped injection route, and intramuscular iron dextran (Imferon) has been questioned with regard to potential carcinogenic properties (Richmond, 1959). Intravenous saccharated iron oxide (Ferrivenin) shares with intramuscular preparations the disadvantage of repeated injections, and has been reported to have a $5 \%$ reaction rate (Laurence and Moulton, 1960).

More recently, the stability of the iron-dextran complex when dissolved in $5 \%$ dextrose has been noted and the possibility of a single infusion of a large quantity of iron in high dilution completely correcting the patient's iron deficit has been welcomed.

- Lately House Surgeons, Hull Maternity Hospital.

\section{Method}

The method involves calculation of the required dose from the manufacturer's tables, correlating the initial haemoglobin and the patient's weight, to a maximum of 2 g., and dissolving it in $5 \%$ dextrose, using a sterile technique, so that the solution is not more than $4 \% \mathrm{v} / \mathrm{v}$. Scrupulous care must be taken to avoid traces of alcohol, detergents, or strong electrolytes contaminating the solution, the giving set, or the site of venepuncture. The infusion is begun at 15 to 20 drops per minute for the first half-hour ; this constitutes the "test dose." The drip is then run at 40 d.p.m. for the remainder of the infusion. As a precaution, all other iron therapy is discontinued for 24 hours prior to treatment by this method.

Over the period of five months, from 1 July 1963, 150 patients were treated in this way at Hull Maternity Hospital. Haematological reports indicated " hypochromic anaemia "with a haemoglobin level of $66 \%$ (Haldane) or less, and no improvement occurred after three weeks on "double oral iron"-that is, ferrous sulphate or ferrous gluconate tabs. 2 t.d.s. All the patients except 22 post-natal cases were in the last trimester of pregnancy, and most were within four to six weeks of term. All had been given oral iron, and the majority said they had taken it.

Of the 150 patients treated, 103 had infusions of $1.5-2 \mathrm{~g}$. of Imferon in $3 \%-4 \%$ solution ; five had infusions of $1-1.5 \mathrm{~g}$. $(2 \%-3 \%$ solution), and 42 had infusions of $1 \mathrm{~g}$. ( $2 \%$ solution). 